\title{
Ativos biológicos: evidenciação e conformidade ao CPC 29 em empresas listadas na B3
}

O estudo tem por objetivo analisar o nível de atendimento e conformidade na evidenciação do CPC 29 pelas empresas listadas na B3. Metodologicamente a pesquisa é de caráter descritivo, com análise documental e de cunho qualitativo. A coleta dos dados considerou as notas explicativas de empresas listadas na B3, que evidenciaram saldos de ativos biológicos em suas demonstrações contábeis nos anos de 2017 e 2018, um checklist foi aplicado para a amostra composta por 18 empresas, a partir de 17 critérios de análise. A análise evidenciou que o atendimento aos critérios do CPC 29 pelas empresas da amostra, atingiu $52,61 \%$ de conformidade em relação ao atendimento ao checklist aplicado, $88,89 \%$ das empresas, apresentaram informações qualitativas ou quantitativas de seus ativos biológicos. A empresa que melhor atendeu as conformidades do CPC 29 foi a Celulose Irani S.A., com índice de conformidade de $81,25 \%$ dos itens do checklist evidenciados. Dentre as 18 empresas da análise, 5 delas evidenciam seus ativos pelo valor justo considerando o mercado ativo, 11 delas realizaram abordagem pelo valor justo, considerando o fluxo de caixa, 7 utilizaram a abordagem pelo método de custo histórico, sendo que apenas 2 delas tem $100 \%$ de seus ativos biológicos mensurados a custo histórico. De forma geral, os resultados destacam os critérios de evidenciação dos ativos biológicos em relação à normativa CPC 29 e as especificidades da avaliação pelo valor justo, quer pelo critério de mercado ativo ou fluxo de caixa.

Palavras-chave: Ativos Biológicos; Valor Justo; CPC 29.

\section{Biological assets: disclosure and compliance with CPC 29 in companies listed in B3} The study aims to analyze the level of service and compliance in the disclosure of CPC 29 by companies listed in B3. Methodologically, the research is descriptive,
with documentary and qualitative analysis. The data collection considered the explanatory notes of companies listed in B3, which showed balances of biological
assets in their financial statements in the years 2015 and 2016 , a checklist was applied to the sample composed of 18 companies, based on 17 analysis criteria. The
analysis showed that the compliance with the CPC 29 criteria by the sample companies reached $52.61 \%$ of conformity in relation to the compliance with the applied
checklist, $88.89 \%$ of the companies, presented qualitative or quantitative information of their biological assets. The company that best met CPC 29 compliance was
Celulose Irani S.A., with a compliance rate of $81.25 \%$ of the evidenced checklist items. Among the 18 companies in the analysis, 5 of them show their assets at fair
value considering the active market, 11 of them took a fair value approach, considering the cash flow, 7 used the historical cost method, and only 2 of them have
$100 \%$ of its biological assets measured at historical cost. In general, the results highlight the criteria for disclosing biological assets in relation to the CPC 29 standard
and the specifics of valuation at fair value, either by the criterion of active market or cash flow.

Keywords: Biological assets; Fair value; CPC 29.

Topic: Contabilidade Pública

Reviewed anonymously in the process of blind peer.
Received: $10 / 10 / 2020$

Approved: 21/12/2020
Nathaniel Antônio Mazetto (id

Universidade Comunitária da Região de Chapecó, Brasil http://lattes.cnpq.br/2931279746480192

http://orcid.org/0000-0003-0048-7771

nathaniel.mazetto@gmail.com

\section{Silvana Dalmutt Kruger (D)}

Universidade Comunitária da Região de Chapecó, Brasil

http://lattes.cnpq.br/0153188470408166

http://orcid.org/0000-0002-3353-4100

silvanak@unochapeco.edu.br

Daniela Di Domenico (iD

Universidade Comunitária da Região de Chapecó, Brasil

http://lattes.cnpq.br/9241444291021630

http://orcid.org/0000-0002-1770-3170

cont@unochapeco.edu.br

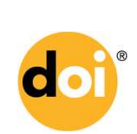

DOI: 10.6008/CBPC2179-684X.2020.004.0018

\author{
Diones Kleinibing Bugalho (iD \\ Universidade Comunitária da Região de Chapecó, Brasil \\ http://lattes.cnpq.br/3406378181071296 \\ http://orcid.org/0000-0002-4636-5086 \\ diones.bugalho@unochapeco.edu.br \\ Francieli Morlin Bugalho (DD \\ Universidade Federal de Santa Catarina, Brasil \\ http://lattes.cnpq.br/7883171339909600 \\ http://orcid.org/0000-0002-7302-5319 \\ fran morlin@hotmail.com
}

\section{Referencing this:}

MAZETTO, N. A.; KRUGER, S. D.; DOMENICO, D. D.; BUGALHO, D. K.; BUGALHO, F. M.. Ativos biológicos: evidenciação e conformidade ao CPC 29 em empresas listadas na B3. Revista Brasileira de Administração Científica, v.11, n.4, p.227-241, 2020. DOI: http://doi.org/10.6008/CBPC2179-684X.2020.004.0018 


\section{INTRODUÇÃO}

A contabilidade é uma ferramenta importante na elaboração de informações voltadas à mensuração e à identificação do desempenho econômico e financeiro das entidades e tomada de decisão (SILVA et al., 2016). O processo decisório demanda informações confiáveis e relevantes e a análise parte das informações apresentadas pela contabilidade (SILVA et al., 2015). Diante do cenário econômico mundial cada vez mais globalizado, a contabilidade brasileira buscou adequar-se por meio da harmonização contábil das empresas brasileiras à contabilidade internacional e permitir uma linguagem universal voltada à comparabilidade das informações (PRADO et al., 2012).

No intuito de reduzir as divergências entre as formas de apresentação das demonstrações contábeis entre os países, no Brasil, foi criado em 2009 o Comitê de Pronunciamentos Contábeis (CPC). O órgão é responsável pela emissão de pronunciamentos técnicos sobre procedimentos de contabilidade denominados CPC's. Tais normas tratam de diferentes aspectos contábeis em conformidade com as Normas Internacionais de Contabilidade (IAS) (SILVA et al., 2016). Especificamente voltado aos ativos biológicos e produtos agrícolas, foi aprovado o Pronunciamento Técnico CPC 29 (2009) que teve como base o International Accounting Standards 41 (IAS 41) (AZEVEDO, 2011).

O CPC 29 estabelece o tratamento e as divulgações dos ativos biológicos e produtos agrícolas nas demonstrações contábeis das empresas brasileiras, visando harmonizar as informações às normas internacionais. Referido CPC (2009) define ativo biológico como um animal ou planta vivos e, define produto agrícola como o produto oriundo desses ativos biológicos. De forma geral, o pronunciamento apresenta vários procedimentos para o tratamento, a mensuração, o reconhecimento de ganhos e perdas (SCHERCH et al., 2013), a descrição de grupos de ativos biológicos, a evidenciação dos métodos e das premissas significativas aplicadas na determinação do valor justo, a divulgação e a apresentação de conciliações sobre os itens classificados como ativos biológicos (WANDERLEY et al., 2012; RODRIGUES et al., 2016).

Referido CPC volta-se às mudanças na mensuração dos ativos biológicos e produtos agrícolas a valor justo menos as despesas de venda (SILVA et al., 2016). Surge assim uma nova forma de avaliar: o valor justo como uma mensuração baseada em mercado para tais itens do balanço patrimonial (VIEIRA et al., 2016). Pode-se constatar que a contabilização de ativos biológicos é assunto discutido em âmbito nacional desde a divulgação do CPC 29, no entanto, é comum encontrar pesquisas que proponham a comparabilidade aos novos métodos propostos pelo CPC 29. Em relação ao CPC 29, pode-se afirmar que a mensuração dos itens do balanço patrimonial voltado aos ativos biológicos e produtos agrícolas, serão representados de uma forma mais justa e confiável para o usuário dessa informação (PLAIS, 2010).

Neste sentido, a problemática que a pesquisa visa responder é: Qual o nível de conformidade na evidenciação ao CPC 29 pelas empresas listadas na B3?. O objetivo do estudo, portanto, é analisar o nível de atendimento e conformidade na evidenciação do CPC 29 pelas empresas listadas na B3. Justifica-se o estudo pela importância de demonstrar a adequada evidenciação das demonstrações contábeis de acordo com a normativa vigente, atendendo da melhor forma os usuários da informação contábil no auxílio à tomada de 
decisão, fornecendo informação fidedigna à situação econômico patrimonial das empresas, possibilitando a comparabilidade e a análise dos critérios utilizados com consonância com a normativa CPC 29.

Ademais, a pesquisa de Arruda et al. (2016), identificou que pela recente adoção às normas internacionais de contabilidade, algumas empresas ainda não atendem totalmente o pronunciamento técnico do CPC 29, o que causa a não conformidade em relação a norma. Portanto, torna-se essencial realizar estudos que avaliem o nível de divulgação pelas empresas o que permite uma maior transparência em relação aos investidores (HOLTZ et al., 2013; FINATELLI et al., 2013).

O artigo está estruturado em cinco seções a contar da introdução. A seção dois apresenta a revisão da literatura e contempla as características dos ativos biológicos conforme o CPC 29. A seção três aborda os procedimentos metodológicos, a seção quatro, a análise realizada e a interpretação dos resultados e a última seção apresenta a conclusão e sugestões de pesquisas futuras.

\section{REVISÃO TEÓRICA}

Nesta seção, apresentam-se as principais características do CPC 29, contemplando os métodos de mensuração dos ativos biológicos, o conceito e a aplicação do valor justo, bem como, os estudos correlatos ao tema da pesquisa desenvolvida.

\section{Finalidade na Mensuração dos Ativos Biológicos conforme o CPC 29}

A representatividade do segmento agrícola no Brasil torna relevante o estudo da forma de registro e divulgação contábil dos ativos biológicos e produtos agrícolas por empresas de diferentes ramos de mercado que possuem tais itens em seus ativos. Essas informações estão diretamente ligadas às demonstrações contábeis elaboradas pela empresa, com impacto na apuração do resultado pela entidade (PLAIS, 2010).

Com o propósito de "[...] estabelecer o tratamento contábil e as respectivas divulgações, relacionadas aos ativos biológicos e aos produtos agrícolas" foi emitido o Pronunciamento Técnico CPC 29 (2009), que também se correlaciona as Normas Internacionais de Contabilidade - IAS 41. No que se refere à aplicabilidade, a aplicação do referido pronunciamento visa proporcionar às empresas que possuem ativos biológicos, diretrizes para que sejam apresentadas informações fidedignas nos resultados patrimoniais, sem intuito ou propósito de apurar resultados positivos ou negativos (SILVA et al., 2016).

As culturas e as criações rurais são denominadas ativos biológicos e se referem a todo animal ou planta vivos e que resultarão em um produto agrícola (FIGUEIRA e RIBEIRO, 2015). A distinção entre produto agrícola e ativo biológico consta no CPC 29 e indica que produto agrícola é oriundo de um ativo biológico da entidade, enquanto o ativo biológico é o ser vivo que deu origem a tal produto (Pronunciamento Técnico CPC-29, 2009). A normativa apresenta alguns exemplos de ativos biológicos, produtos agrícolas e do que podem ser tratados como produtos oriundos da colheita e/ou produção desses ativos biológicos, conforme demonstrado no Quadro 1:

O Quadro 1 apresenta exemplos de ativos biológicos, produtos agrícolas e produtos que são originados dos produtos agrícolas extraídos dos ativos biológicos, tratados como produto resultante do 
processamento após a colheita. De acordo com Barreto et al. (2016), a ênfase para o estudo, mensuração e evidenciação dos ativos biológicos se dá durante a fase de transformação biológica, sempre demonstrando que a forma de mensuração se alterna entre o valor justo e o custo histórico, especialmente em casos que não há mercado ativo para a valoração pelo valor justo, utilizando-se então, da mensuração pelo custo histórico.

Quadro 1: Exemplos de ativos biológicos e produtos agrícolas.

\begin{tabular}{|l|l|l|}
\hline Ativos Biológicos & Produto Agrícola & Produtos resultantes do processamento após a colheita \\
\hline Carneiros & Lã & Fio, tapete \\
\hline Árvores em uma plantação & Madeira & Madeira serrada, celulose \\
\hline Plantas & $\begin{array}{l}\text { Algodão } \\
\text { Cana colhida Café }\end{array}$ & $\begin{array}{l}\text { Fio de Algodão, roupa Açúcar, álcool } \\
\text { Café limpo em grão, moído, torrado. }\end{array}$ \\
\hline Gado de Leite & Leite & Queijo \\
\hline Porcos & Carcaça & Salsicha, presunto \\
\hline Arbustos & Folhas & Chá, tabaco \\
\hline Videiras & Uva & Vinho \\
\hline Árvores Frutíferas & Fruta colhida & Fruta processada \\
\hline
\end{tabular}

Fonte: Pronunciamento Técnico CPC 29 (2009).

A transformação biológica dos ativos, em casos de alteração de qualidade, crescimento, evolução ou alteração de característica do ativo, deve ser evidenciada nos resultados da empresa e resulta dos seguintes eventos: (a) mudanças de ativos por meio de (i) crescimento (aumento em quantidade ou melhoria na qualidade do animal ou planta), (ii) degeneração (redução na quantidade ou deterioração na qualidade de animal ou planta) ou (iii) procriação (geração adicional de animais ou plantas); ou (b) produção de produtos agrícolas, tais como látex, folhas de chá, lã, leite (CPC, 2009).

Os ativos biológicos, principalmente no ramo da agricultura, compreendem uma série de atividades nas quais é possível identificar diversas características que não podem ser ignoradas pela contabilidade (EINSWEILLER et al., 2013). Por se tratar de ativos vivos, apresentam alterações biológicas, como, por exemplo: crescimento, morte, perda ou aumento de produtividade e mudanças de características. Para que a entidade reconheça no balanço, os ativos biológicos e produtos agrícolas devem ser controlados pela entidade, ter a comprovação de que trarão ou poderão trazer benefícios econômicos futuros e o seu valor justo ou custo histórico possa ser mensurado de forma confiável (CPC, 2009).

Kruger et al. (2014) exemplificam ainda, que ativos consumíveis são os que se tornarão produtos agrícolas, a exemplo do gado destinado a venda ou produção de carne, os ativos de produção por sua vez são os que originam os produtos agrícolas, assim como a matriz leiteira que fornece o leite.

\section{Valor Justo versus Custo Histórico}

O valor justo é definido como "[...] o preço que seria recebido pela venda de um ativo ou que seria pago pela transferência de um passivo em uma transação não forçada entre participantes do mercado na data de mensuração" (CPC, 2012). Ainda segundo o referido pronunciamento, o valor justo é uma forma de mensurar ativos e passivos de acordo com o mercado e não uma mensuração específica adotada pela entidade, sendo utilizado para a avaliação de ativos biológicos, e também para outros grupos de ativos.

A nova abordagem de avaliação de itens do balanço, especialmente ativos biológicos a valor justo, 
faz com que exista maior transparência nas demonstrações contábeis da empresa, e torna necessária a evidenciação de todo e qualquer efeito provocado no patrimônio decorrente da adoção desse critério (WANDERLEY et al., 2012). A utilização do valor justo na mensuração dos ativos biológicos é orientação prevista tanto nas normas internacionais de contabilidade quanto no Pronunciamento Técnico CPC 29 (2009). Quanto à evidenciação nas demonstrações contábeis "o ganho ou perda da mensuração do valor justo menos o custo de vender deverá ser registrado no resultado líquido do exercício, tendo como contrapartida a conta do ativo referente ao ativo biológico ou produto agrícola" (PLAIS, 2010).

Não obstante o exposto, Einsweiller et al. (2013), destacam que há algumas contradições quanto ao valor justo como método de mensuração, por não conter uma forma objetiva e consistente de valoração. Já o custo histórico, contém documentos comprobatórios do valor registrado, sendo caracterizado como contabilmente confiável, relatam os autores. No entanto, destacam que a mensuração pelo valor justo é algo de maior complexidade e requer notas explicativas com os critérios e métodos utilizados para sua avaliação.

O custo histórico representa o registro dos valores recebidos ou desembolsados na data da aquisição e na qual ativos e passivos são registrados (SILVA et al., 2015). O custo histórico é considerado por Prado et al. (2012) como uma espécie de máscara para a economia da empresa, pois o bem avaliado dificilmente continuará com o mesmo valor do registro constante nas demonstrações contábeis, em contrapartida, o valor justo proporciona aos investidores uma maior certeza do valor desse bem.

A entidade deve mensurar o valor justo de um ativo ou passivo utilizando as premissas que os participantes do mercado utilizariam ao precificar o ativo ou o passivo, presumindo-se que os participantes do mercado ajam em seu melhor interesse econômico, um exemplo para esta aplicação é quando uma entidade adquire um imóvel, mas resolve não o utilizar. Independentemente da decisão da empresa, esse imóvel deverá ser mensurado pelo valor que ele poderia ser vendido, considerando o seu mais eficiente uso. (CPC, 2012). Para encontrar o valor justo, existem algumas técnicas de avaliação para estimativa de preço. $O$ CPC 46 (CPC, 2012) prevê que a entidade deve abordar uma entre as três técnicas utilizadas: a abordagem de mercado, a abordagem de custo e ou, a abordagem de receita, para avaliação e mensuração do valor justo. O Quadro 2 resume as abordagens de mensuração do valor justo.

Quadro 2: Abordagens de mensuração do valor justo.

\begin{tabular}{|l|l|}
\hline Abordagem & Conceito \\
\hline Abordagem de mercado & $\begin{array}{l}\text { Utiliza transações reais de mercado envolvendo ativos, passivos ou grupo de ativos e passivos, ela leva } \\
\text { todas as informações relevantes que deverão ser consideradas no momento de realizar a mensuração. }\end{array}$ \\
\hline Abordagem de custo & $\begin{array}{l}\text { A abordagem de custo é o custo necessário de reposição na substituição do bem em questão por } \\
\text { eventual venda ou baixa na data da mensuração. }\end{array}$ \\
\hline $\begin{array}{l}\text { Abordagem de receita } \\
\text { técnica do fluxo de caixa }\end{array}$ & $\begin{array}{l}\text { Én conversão de valores futuros, prevendo receitas e despesas e transformando esse valor em um valor } \\
\text { único atual. Essa abordagem reflete a expectativa real de mercado em relação aos valores futuros dos } \\
\text { ativos em questão. }\end{array}$ \\
\hline
\end{tabular}

Fonte: Adaptado do Pronunciamento Técnico CPC 46 (2012).

Como se pode observar, o Quadro 2 apresenta as características das técnicas de abordagem para mensuração do valor justo. Tais abordagens são preceitos básicos para a mensuração do item a ser demonstrado contabilmente e devem ser escolhidas de acordo com a situação, podendo ser utilizadas de forma conjunta ou não. Segundo Talaska et al. (2016), um exemplo de abordagem de mercado bastante 
corriqueira se dá no ramo da pecuária de corte, na qual as informações baseiam-se no valor da arroba bovina comercializada na data do fechamento das demonstrações contábeis, as mutações patrimoniais decorrentes das alterações genéticas dos ativos biológicos ficam baseadas na mensuração pelo valor justo. Como comprovação da importância da correta mensuração dos ativos biológicos, "a depreciação ganha relevância a partir do momento em que a entidade apresenta direcionamento para os critérios estabelecidos no CPC 27", diferindo das taxas indicadas pelas legislações fiscais (MARTINS et al., 2014).

A mensuração pelo valor justo tem por base o mercado e se registra o ativo pelo preço que seria recebido em uma transação não forçada entre partes interessadas na data da mensuração (CPC, 2012). Esse preço, segundo o pronunciamento não deve ter ajustes provenientes de custos de aquisição e, na ausência de mercado ativo para avaliação do bem pelo valor justo, a orientação é que seja utilizado o custo histórico.

Por fim, Macedo et al. (2015) afirmam que os investidores passaram a ter maior confiabilidade nas demonstrações contábeis após a implantação da obrigatoriedade das mensurações a valor justo, por retratar de uma forma mais relevante as informações econômicas e financeiras da empresa, já que os usuários externos não têm acesso às informações de natureza gerencial da entidade.

\section{Estudos anteriores}

Para subsidiar este estudo, também foram consultados estudos anteriores que evidenciaram a utilização e mensuração dos itens contemplados pelo Pronunciamento Técnico CPC 29 (2009), ativos biológicos e produtos agrícolas. Em função da limitação do número de páginas para esta publicação, são relacionados de forma sucinta os principais estudos.

Barros et al. (2012) analisaram o impacto da mensuração a valor justo dos ativos biológicos das empresas listadas na BM\&FBOVESPA nos exercícios de 2008 a 2010 e destacaram o impacto na evidenciação dos ativos biológicos, que apresentaram valores com variação crescente no período.

Carvalho et al. (2013) analisaram a adoção do CPC 29 entre as empresas listadas no ano de 2010 no Índice Ibovespa. Identificaram a adoção antecipada da norma por 5 empresas, apesar de uma não ter evidenciado informações sobre ativos biológicos nas demonstrações contábeis anuais.

Foi efetuado um estudo para verificar a divulgação das informações contábeis sobre a mensuração dos ativos biológicos em demonstrações contábeis das companhias listadas na BM\&FBOVESPA, no período 2008 a 2012. O fluxo de caixa descontado foi o método mais utilizado para a definição do valor justo, mas foi escassa a evidenciação dos ativos biológicos de acordo com o CPC 29.

Macedo et al. (2015) verificaram o nível de conformidade com o CPC 29 e a associação com características empresariais nas empresas brasileiras de capital aberto que possuíam ativos biológicos em 2013. Constataram que o setor de alimentos e bebidas teve a maior percentual de conformidade, seguido pelos setores de madeira e papel e, pesca e agropecuária. Identificaram ainda que o tamanho da empresa teve interação significativa com o nível de conformidade.

Prado et al. (2012) avaliaram o impacto das alterações ocorridas pelos critérios obrigatórios de contabilização dos ativos biológicos, em três empresas brasileiras do setor agropecuário listadas na 
BM\&FBOVESPA, nos exercícios de 2009 e 2010. Concluíram que a aplicação da normativa às empresas do setor agrícola apresentou grande impacto nas demonstrações contábeis nos períodos estudados. O foco da pesquisa foi apresentar a importância da mensuração fidedigna contábil aos usuários para a real perspectiva da situação econômica das empresas.

Wanderley et al. (2012) avaliaram o grau de observância das disposições do CPC 29 em relação aos ativos biológicos em três empresas listadas na BM\&FBOVESPA do setor de alimentos processados/carnes e derivados referente a 2009 e 2010. Concluíram pela necessidade de melhorar o atendimento ao CPC 29 e uma avaliação fidedigna dos resultados.

Machado et al. (2016) verificaram o atendimento a normativa contábil das empresas brasileiras listadas na B3 no ano de 2013, que possuíam ativos biológicos, buscando identificar a divulgação voluntária e obrigatória desses ativos, concluiu em sua pesquisa que de todas as entidades analisadas nenhuma atende por completo o que exige o pronunciamento contábil CPC 29, embora ao comparar o nível de divulgação de anos anteriores pode-se observar um aumento significativo no que diz respeito à divulgação obrigatória.

Talaska et al. (2016) analisaram o nível de disclosure de ativos biológicos nas empresas listadas na BM\&FBOVESPA após a adoção do método de mensuração pelo valor justo, nos anos de 2011 a 2013. Constataram que, apesar da grande variação no nível de evidenciação entre as empresas, o nível de adequação às normas contábeis ficou distante dos padrões estabelecidos pelo CPC 29.

De forma geral, as pesquisas demonstram a importância da adequação das empresas ao CPC 29, trazendo casos de incidência parcial ou total e algumas pesquisas de estudo comparando a nova norma às formas antigas de se mensurar ativos biológicos. Todas, indiferente do resultado, demonstraram a dificuldade em implantar toda a normativa, muitas vezes, pela inexistência de mercado ativo do bem mensurado. Em contrapartida à dificuldade relatada, a informação contábil com confiabilidade e números relevantes, traz o benefício da segurança de demonstrações contábeis fidedignas à realidade da empresa.

\section{METODOLOGIA}

Metodologicamente o estudo caracteriza-se como descritivo que segundo Raupp et al. (2004), caracteriza-se como "um estudo intermediário entre a pesquisa exploratória e a explicativa, ou seja, não é tão preliminar como a primeira nem tão aprofundada como a segunda. Neste contexto descrever significa identificar, relatar, comparar, entre outros aspectos". O procedimento de coleta de dados é caracterizado por análise documental que de acordo com Gil (2010) "a pesquisa documental vale-se de toda sorte de documentos, elaborados com finalidades diversas, tais como relatórios, autorização, comunicação, etc." Em relação a abordagem trata-se de uma pesquisa qualitativa que de acordo com o estudo de Raupp et al. (2004), "concebem-se análises mais profundas em relação ao fenômeno que está sendo estudado. A abordagem qualitativa visa destacar características não observadas por meio de um estudo quantitativo, haja vista a superficialidade deste último".

Quanto aos procedimentos utilizados para atender ao objetivo de analisar o nível de conformidade na evidenciação do Pronunciamento Técnico CPC 29 (2009) pelas empresas listadas na B3 proposto, efetuou- 
se a coleta de informações das empresas listadas e que evidenciaram ativos biológicos em suas demonstrações contábeis consolidadas nos anos de 2017 e 2018. A coleta de dados foi realizada nos sítios da B3 e da CVM. A amostra da pesquisa foi composta por 18 empresas que constam relacionadas, juntamente com a respectiva classificação setorial na seção dos resultados.

A partir das demonstrações e das notas explicativas, foi aplicado um checklist, baseado no estudo de Macedo et al. (2015), visando identificar o atendimento ou não dos procedimentos exigidos pela normativa CPC 29, o checklist aplicado permite observar a síntese do atendimento aos 17 critérios de análise estabelecidos, contemplando a abordagem do problema da pesquisa e os procedimentos de análise são predominantemente de cunho qualitativo. Os resultados são apresentados na seção seguinte.

\section{RESULTADOS E DISCUSSÃO}

Após a coleta, os dados foram examinados com base em um checklist para verificar as exigências da normativa CPC 29. A Tabela 1 apresenta os itens de divulgação do CPC 29 analisados nos relatórios das empresas, com a síntese do atendimento aos critérios do checklist aplicado.

Tabela 1: Itens de divulgação do CPC 29 analisados nos relatórios das empresas

\begin{tabular}{|c|c|c|c|c|}
\hline \multirow[b]{2}{*}{ Critérios } & \multicolumn{2}{|c|}{2018} & \multicolumn{2}{|l|}{2017} \\
\hline & \begin{tabular}{l|} 
Empresas \\
Aplicadas
\end{tabular} & \begin{tabular}{|l|}
$\%$ \\
Conformidade
\end{tabular} & $\begin{array}{l}\text { Empresas } \\
\text { Aplicadas }\end{array}$ & $\begin{array}{l}\% \\
\text { Conformidade }\end{array}$ \\
\hline $\begin{array}{l}\text { Divulgou ganho ou perda em relação ao valor inicial do ativo biológico e } \\
\text { decorrentes da mudança no valor justo dos ativos biológicos? }\end{array}$ & 18 & $66,67 \%$ & 18 & $66,67 \%$ \\
\hline $\begin{array}{l}\text { A entidade forneceu uma descrição de ativos biológicos (dissertativa ou } 1 \\
\text { quantitativa)? }\end{array}$ & 18 & $88,89 \%$ & 18 & $88,89 \%$ \\
\hline $\begin{array}{l}\text { Forneceu a quantidade de cada grupo de ativos biológicos, distinguindo entre } \\
\text { consumíveis e de produção ou entre maduros e imaturos? }\end{array}$ & 18 & $83,33 \%$ & 18 & $72,22 \%$ \\
\hline \begin{tabular}{|l|l} 
A natureza de cada grupo de ativos biológicos? & 1 \\
\end{tabular} & 18 & $94,44 \%$ & 18 & $94,44 \%$ \\
\hline $\begin{array}{l}\text { Mensurações não financeiras de quantidades físicas de cada grupo no final do } \\
\text { período e/ou da produção agrícola durante o período? }\end{array}$ & 18 & $22,22 \%$ & 18 & $22,22 \%$ \\
\hline $\begin{array}{l}\text { A existência e o total de ativos biológicos cuja titularidade legal seja restrita, e o } \\
\text { montante deles dado como garantia de exigibilidades? }\end{array}$ & 18 & $38,89 \%$ & 18 & $38,89 \%$ \\
\hline $\begin{array}{l}\text { O montante de compromissos relacionados com o desenvolvimento de ativos } 1 \\
\text { biológicos? }\end{array}$ & 18 & $5,56 \%$ & 18 & $5,56 \%$ \\
\hline $\begin{array}{c}\text { As estratégias de administração de riscos financeiros relacionadas } \\
\text { com a atividade agrícola? }\end{array}$ & 18 & $27,78 \%$ & 18 & $27,78 \%$ \\
\hline $\begin{array}{l}\text { Conciliação das alterações no valor de ativos biológicos entre o início e o fim do } 1 \\
\text { período? }\end{array}$ & 18 & $83,33 \%$ & 18 & $83,33 \%$ \\
\hline Uma descrição dos ativos biológicos? & 17 & $88,24 \%$ & 17 & $82,35 \%$ \\
\hline $\begin{array}{l}\text { Uma explicação da razão pela qual o valor justo não pode ser mensurado de } 1 \\
\text { forma confiável? }\end{array}$ & 15 & $40,00 \%$ & 15 & $40,00 \%$ \\
\hline $\begin{array}{l}\text { Uma faixa de estimativas onde existe alta probabilidade de se encontrar o valor } 1 \\
\text { justo? }\end{array}$ & 13 & $15,38 \%$ & 13 & $15,38 \%$ \\
\hline \begin{tabular}{|l|l} 
O método de depreciação utilizado? & 1 \\
\end{tabular} & 17 & $82,35 \%$ & 17 & $82,35 \%$ \\
\hline A vida útil ou a taxa de depreciação utilizada? & 17 & $70,59 \%$ & 17 & $70,59 \%$ \\
\hline \begin{tabular}{|l|l} 
O total bruto e a depreciação acumulada no início e no final do período? & 1 \\
\end{tabular} & 17 & $58,82 \%$ & 17 & $58,82 \%$ \\
\hline $\begin{array}{l}\text { Apresentou as perdas e reversão de perdas irrecuperáveis e as depreciações do } 1 \\
\text { período? }\end{array}$ & & $20,00 \%$ & 15 & $20,00 \%$ \\
\hline $\begin{array}{l}\text { Caso o valor justo dos ativos biológicos, previamente mensurados ao custo, } \\
\text { menos qualquer depreciação e perda no valor recuperável acumulada se tornar } \\
\text { mensurável de forma confiável durante o período corrente, a entidade divulgou } \\
\text { uma descrição dos ativos biológicos, uma explicação da razão pela qual a } 1 \\
\text { mensuração do valor justo se tornou mensurável de forma confiável, e o efeito } \\
\text { da mudança? }\end{array}$ & & $0,00 \%$ & 16 & $0,00 \%$ \\
\hline
\end{tabular}


Pode ser observado na Tabela 1 o percentual de conformidade das empresas, nos anos de 2017 e 2018, ao CPC 29 quanto aos ativos biológicos, em diferentes critérios. Chama a atenção o fato de que, apesar de aplicável a 16 empresas analisadas, nenhuma atendeu ao último item do checklist. A falta de conformidade decorre do fato de mesmo apresentando os ativos biológicos mensurados a método de custo histórico, nenhuma empresa informou valores de perda a valor recuperável dos seus ativos de forma confiável nos dois períodos abordados.

$\mathrm{O}$ item do checklist que demonstrou maior conformidade dentro da amostra destacou que 17 empresas analisadas fizeram referência à natureza das atividades envolvendo os ativos biológicos nas demonstrações contábeis. Em geral, os itens de maior percentual de à adequação à normativa são os itens voltados aos casos nos quais o valor o valor justo é mais facilmente mensurado, geralmente pela existência de mercado ativo. Em 88,89\% das empresas, são apresentadas informações qualitativas ou quantitativas dos ativos biológicos, sendo que 88,24\% das empresas mencionam os ativos biológicos e as devidas destinações. O método de depreciação utilizado foi evidenciado em $82,35 \%$ das empresas da análise. A exaustão é o método mais evidenciado, o que se deve a maioria das empresas possuir florestas e animais para abate. A quantidade de cada grupo de ativos biológicos e respectiva distinção entre consumíveis e de produção ou entre maduros e imaturos foi evidenciada por $83,33 \%$ das empresas. Idêntico percentual de empresas efetuou a conciliação no valor de ativos biológicos entre o início e o fim do período.

Entre os itens de baixa evidenciação, apenas 15,38\% das empresas apresentaram faixa de estimativas de alta probabilidade de se encontrar o valor justo; $20 \%$ as perdas e reversão de perdas irrecuperáveis e as depreciações do período; $27,78 \%$ as estratégias de administração de riscos financeiros relacionadas com a atividade agrícola. $\mathrm{O}$ item que questiona sobre a razão ou explicação para que o valor justo não possa ser mensurado de forma confiável foi evidenciado em $40 \%$ das empresas analisadas. Por não existir mercado ativo, algumas empresas abordam a técnica do fluxo de caixa, mas em alguns casos o critério não foi seguido pela justificativa de que o custo histórico bem próximo ao valor justo dos ativos.

A partir das classificações setoriais utilizadas pelo índice da B3, que identifica os ramos de mercado que cada empresa atua, a Tabela 2 apresenta as empresas analisadas, respectiva classificação setorial e o percentual de evidenciação em conformidade com o Pronunciamento Técnico CPC 29 (2009).

Observa-se na Tabela 2 que a média geral de conformidade das 18 empresas da amostra é de 52,61\%. A empresa com maior conformidade geral (81,25\%) foi a Celulose Irani S.A., que atendeu a 13 dos 17 itens verificados. Pode-se afirmar que houve evolução na evidenciação dos ativos biológicos se comparado ao percentual médio de 30\% referente ao período 2008 a 2010 encontrado por Barros et al. (2012). Referidos autores defenderam que os baixos índices refletiam a não obrigatoriedade da normativa em 2008, com tendência de melhora nas evidenciações pela obrigatoriedade imposta a partir de 2009.

Entre os 8 setores analisados, o de maior incidência de empresas é o de madeira e papel, com 6 empresas listadas e, conformidade média de 61,39\% dos itens do checklist, com ênfase para a Celulose Irani S.A. Esses resultados assemelham-se ao estudo de Carvalho et al. (2013) com base nas demonstrações de 2010 e que, em relação ao mesmo setor, concluiu que apresentava os melhores índices de evidenciação do 
ativo biológico em conformidade com o CPC 29. No entanto, a Karsten S.A. não apresentou nas notas explicativas informação sobre os ativos biológicos, apesar do saldo de $\mathrm{R} \$ 460.000,00$ na conta de Ativo Biológico - ANC nos anos de 2017 e 2018. Isso contribuiu para que a classificação setorial tecidos, vestuário e calçados seja a de menor conformidade, com apenas $8,82 \%$ dos itens atendidos.

Tabela 2: Agrupamento das empresas listadas por classificação setorial e suas conformidades

\begin{tabular}{|c|c|c|c|c|c|}
\hline & & Itens & Itens & $\% \quad$ Conformidade $\%$ & $\% \quad$ Médio \\
\hline Classificação Setorial & Nome da Empresa & Aplicados & Conformidade & \begin{tabular}{|l|l} 
Empresa & C
\end{tabular} & Conformidade Setor \\
\hline \multirow[t]{2}{*}{ Agropecuária / Agricultura } & $\begin{array}{l}\text { Brasilagro - Cia Bras. de } \\
\text { Prop. Agrícolas }\end{array}$ & 16 & 7 & $43,75 \%$ & \multirow[t]{2}{*}{$48,48 \%$} \\
\hline & SLC Agrícola S.A. & 17 & 9 & $52,94 \%$ & \\
\hline \multirow{4}{*}{$\begin{array}{l}\text { Alimentos processados } \\
\text { Carnes e derivados }\end{array}$} & BRF S.A. & 12 & 8 & $66,67 \%$ & \multirow{4}{*}{$56,36 \%$} \\
\hline & JBS S.A. & 17 & 11 & $64,71 \%$ & \\
\hline & Marfrig Global Foods S.A. & 17 & 7 & $41,18 \%$ & \\
\hline & Minerva S.A. & 9 & 5 & $55,56 \%$ & \\
\hline $\begin{array}{l}\text { Bens industriais / Material de } \\
\text { transporte }\end{array}$ & $\begin{array}{l}\text { WLM Indústria e Comércio } \\
\text { S.A. }\end{array}$ & 15 & 11 & $73,33 \%$ & $73,33 \%$ \\
\hline $\begin{array}{l}\text { Bens industriais / Transporte } \\
\text { hidroviário }\end{array}$ & Trevisa Investimentos S.A. & 17 & 10 & $58,82 \%$ & $58,82 \%$ \\
\hline $\begin{array}{l}\text { Intermediários } \\
\text { financeiros / Bancos }\end{array}$ & $\begin{array}{l}\text { Itaúsa Investimentos Itaú } \\
\text { S.A. }\end{array}$ & 17 & 8 & $47,06 \%$ & $47,06 \%$ \\
\hline \multirow{6}{*}{$\begin{array}{l}\text { Madeira e papel / Papel e } \\
\text { celulose }\end{array}$} & Celulose Irani S.A. & 16 & 13 & $81,25 \%$ & \multirow{6}{*}{$61,39 \%$} \\
\hline & \begin{tabular}{|l|} 
Duratex S.A. \\
\end{tabular} & 17 & 11 & $64,71 \%$ & \\
\hline & Fibria Celulose S.A. & 17 & 9 & $52,94 \%$ & \\
\hline & Klabin S.A. & 17 & 7 & $41,18 \%$ & \\
\hline & Suzano Holding S.A. & 17 & 11 & $64,71 \%$ & \\
\hline & $\begin{array}{l}\text { Suzano Papel e Celulose } \\
\text { S.A. }\end{array}$ & 17 & 11 & $64,71 \%$ & \\
\hline $\begin{array}{l}\text { Siderurgia e metalurgia / } \\
\text { Siderurgia }\end{array}$ & $\begin{array}{l}\text { Cia Ferro Ligas da Bahia - } \\
\text { Ferbasa }\end{array}$ & 15 & 10 & $66,67 \%$ & $66,67 \%$ \\
\hline \multirow[t]{2}{*}{ Tecidos. Vestuário e calçados } & Grazziotin S.A. & 17 & 3 & $17,65 \%$ & \multirow[t]{2}{*}{$8,82 \%$} \\
\hline & Karsten S.A. & 17 & 0 & $0,00 \%$ & \\
\hline
\end{tabular}

Pode-se observar grande variação entre os níveis de evidenciação entre empresas, por exemplo, Karsten S.A. e Celulose Irani S.A. Isso vai ao encontro dos resultados obtidos por Talaska et al. (2016) que analisaram o período de 2011 a 2013 das empresas listadas na B3, também encontraram empresas com altos índices de conformidade ao CPC 29 em contrapartida a outras, omissas quanto à legislação vigente. A empresa Itaúsa Investimentos Itaú S.A., apresenta uma conformidade de 47,06\% dos itens do checklist do CPC 29. Controla a Itausa, Duratex Florestal Ltda., Tablemac S.A. e Caetex Florestal S.A., essas, com reservas florestais de pinus e eucalipto, o que justifica a existência de ativo biológico da empresa cuja classificação setorial não demandaria essa atividade.

Para fins de especificação das diferentes classificações setoriais da B3 e para entender qual a aplicação dos ativos biológicos das empresas listadas em cada um dos setores, a Tabela 3 aborda os setores que apresentam ativos biológicos mantidos como itens de curto prazo. Entende-se por ativo de curto prazo ou ativo circulante os bens e direitos da empresa que se espera sua realização dentro de um período de até 12 meses.

Os setores de agropecuária, alimentos processados e bens industriais são os grupos que apresentam ativos biológicos que se esperam realização em menor período. Conforme a Tabela 3, percebe-se que o setor de alimentos processados e carnes e derivados têm o saldo de ativo total extremamente maior que os totais 
dos demais setores. Isso se dá pelas empresas possuírem unidades fabris de grande potencial produtivo, com máquinas e equipamentos que incorporam valor tão grande ao ativo apresentado nas notas explicativas. Em contrapartida, é o setor com menor representatividade de ativos biológicos a curto prazo em relação ao ativo total no ano de 2017. Os resultados desta pesquisa assemelham-se aos de Macedo et al. (2015), que também evidenciou que o setor de alimentos e bebidas, apesar de possuir porcentagem pequena em relação ao ativo total, representou o maior valor monetário comparado aos demais setores.

Tabela 3: Setores que apresentam ativos biológicos a curto prazo.

\begin{tabular}{l|l|l|l|l|l|l}
\hline Classificação Setorial & Total Ativo & \multicolumn{3}{l}{ Ativo biológico de Curto Prazo } \\
\cline { 2 - 7 } & $\mathbf{2 0 1 8}$ & $\mathbf{2 0 1 7}$ & $\mathbf{2 0 1 8}$ & $\mathbf{\%}$ & $\mathbf{2 0 1 7}$ & $\%$ \\
\hline Agropecuária/Agricultura & 6.307 .205 & 6.327 .473 & 521.174 & 8,26 & 425.329 & 6,72 \\
\hline Alimentos processados / Carnes e derivados & 174.978 .650 & 191.806 .508 & 4.572 .209 & 2,61 & 4.566 .835 & 2,38 \\
\hline Bens industriais / Material de transporte & 518.539 & 518.925 & 12.297 & 2,37 & 8.563 & 1,65 \\
\hline
\end{tabular}

As empresas do ramo da agricultura têm como seus principais produtos o plantio de milho e de soja, que são culturas que se realizam no máximo em 10 meses. Essas culturas estão classificadas no ativo circulante (curto prazo). Mesmo com um ativo total menor em relação ao setor de alimentos processados, agricultura e agropecuária é o setor de maior representatividade de ativos biológicos a curto prazo, com 8,26\% em 2018 e 6,72\% em 2017.

O setor de bens industriais/material de transporte é representado pela WLM Indústria e Comércio S.A. Nas suas notas explicativas estão registrados a curto prazo os rebanhos em formação e aos bezerros de idade de 0 a 7 meses. Esses rebanhos estão evidenciados a curto prazo para que que a WLM mantenha uma segregação de idade na classificação dos rebanhos, uma tática usada para melhor mensurar o valor justo desse tipo de ativo biológico.

Pode-se verificar que todas as classificações setoriais apresentaram ativos biológicos em pelo menos um dos anos da análise. O destaque fica para o setor de bens industriais/material de transporte que apresentou ativos biológicos a longo prazo apenas no período de 2017. A WLM Indústria e Comércio S.A. é a única empresa analisada classificada nesse setor e, de acordo com as notas explicativas divulgadas no ano de 2018, demonstrou valor zerado nos ativos biológicos a longo prazo; a explicação é que o rebanho foi mantido para venda e transferido para o curto prazo.

A Tabela 4 apresentada a seguir, traz informações sobre as classificações setoriais das empresas que apresentaram ativos biológicos a longo prazo. No ativo não circulante estão registrados os ativos que a empresa espera realização após 12 meses do encerramento do exercício atual.

Tabela 4: Setores que apresentam ativos biológicos a longo prazo.

\begin{tabular}{|c|c|c|c|c|c|c|}
\hline \multirow[t]{2}{*}{ Classificação Setorial } & \multicolumn{2}{|l|}{ Total Ativo } & \multicolumn{4}{|c|}{ Ativo Biológico de Longo Prazo } \\
\hline & 2018 & 2017 & 2018 & $\%$ & 2017 & $\%$ \\
\hline Agropecuária/Agricultura & 6.307 .205 & 6.327 .473 & 44.530 & 0,71 & 29.245 & 0,46 \\
\hline Alimentos processados / Carnes e derivados & 174.978 .650 & 191.806 .508 & 1.738 .062 & 0,99 & 2.017 .698 & 1,05 \\
\hline Bens industriais / Material de transporte & 518.539 & 518.925 & - & - & 6.300 & 1,21 \\
\hline $\begin{array}{lll}\text { Bens } & \text { industriais / Transporte hidroviário }\end{array}$ & 187.566 & 174.145 & 34.885 & 18,60 & 34.603 & 19,87 \\
\hline Intermediários financeiros / Bancos & 59.020 .000 & 54.830 .000 & 1.529 .000 & 2,59 & 1.442 .000 & 2,63 \\
\hline Madeira e papel / Papel e celulose & 133.676 .734 & 123.250 .732 & 17.917 .617 & 13,40 & 17.685 .523 & 14,35 \\
\hline Siderurgia e metalurgia / Siderurgia & 1.657 .620 & 1.645 .142 & 197.886 & 11,94 & 188.902 & 11,48 \\
\hline Tecidos. Vestuário e calçados & 644.147 .765 & 577.574 .318 & 18.924 .172 & 2,94 & 19.677.540 & 3,41 \\
\hline
\end{tabular}


O setor com maior representatividade de ativos biológicos classificados no ativo não circulante é o setor de bens industriais/transporte hidroviário, representado apenas por uma empresa, a Trevisa Investimentos S.A., que mantém ativos biológicos dentro de uma das empresas controladas, a Trevo Florestal Ltda., que possui florestas de pinus e eucaliptos, além de rebanho bovino destinado a reprodução.

O setor de papel e celulose é o segundo setor com maior representatividade de ativos biológicos evidenciados a longo prazo em relação ao ativo total. De forma geral, essa classificação é formada por empresas que evidenciam florestas de pinus e florestas de eucalipto que são mantidas para posterior geração de matéria-prima para a produção industrial de papel e fornecimento de material para terceiros.

Das empresas representantes do setor de tecidos e vestuário, a Karsten S.A., em suas notas explicativas não traz informação sobre o que compõe o saldo de seus ativos biológicos e qualquer outra informação; a única informação é um saldo de ativo biológico registrado a longo prazo que se mantém constante nos dois anos da análise. Já a Grazziotin S.A. tem saldos de ativos biológicos na sua controlada, a Grato Agropecuária Ltda., indicando lavouras de soja e milho, o que caberia a reclassificação para o ativo circulante, tendo em vista o período de realização destas culturas.

$\mathrm{Na}$ comparação entre curto de longo prazo, o setor de alimentos processados apresenta praticamente metade dos valores de ativos biológicos a longo prazo do que a curto prazo. Isso decorre dos ativos de curto prazo do setor serem, de modo geral, animais com vida mais curta, como frangos e suínos, cujo confinamento dura meses. Também o rebanho de gado, mesmo com vida mais longa, é mantido a curto prazo pela finalidade de comercialização; assim, o que a Tabela 4 evidenciou foram matrizes com finalidade de recria e, portanto, classificadas como ativos não circulantes.

Verificou-se que a maioria das empresas evidenciou os ativos biológicos conforme orientações do CPC 29, apresentando nas demonstrações contábeis o valor justo, ponderado o mercado ativo ou a abordagem pelo fluxo de caixa, sendo indicada a utilização da última quando não houver mercado ativo para o ativo biológico. Os resultados sobre a mensuração de ativos biológicos pelo valor justo utilizando a técnica de fluxo de caixa descontado assemelham-se aos resultados encontrados por Figueira e Ribeiro (2015) em análise à 30 empresas listadas no BM\&FBOVESPA no período 2008 a 2012; o estudo evidenciou que o fluxo de caixa descontado foi a técnica mais utilizada para a avaliação dos itens ativos biológicos, pela falta de mercado ativo para servir como base na mensuração do valor justo.

Entre as empresas analisadas, Grazziottin S.A. e SLC Agrícola S.A. não avaliam nenhum de seus ativos biológicos a valor justo. A justificativa de ambas é de que o custo de produção se assemelha muito ao valor justo, portanto, se faz desnecessária a abordagem a valor justo, pelo ajuste ser algo imaterial. No entanto, todas as empresas que mantém rebanho bovino em seus ativos avaliam esse ativo biológico a valor de mercado, método considerado de maior confiabilidade, pois de baseia nos fechamentos diários dos órgãos competentes e no qual a variação segue índices do boi gordo da B3 e, os contratos geralmente são firmados de acordo com a cotação da arroba de gado do dia.

Em relação ao valor justo como método de avaliação dos ativos biológicos, o Quadro 3 apresenta, além das empresas da análise, o tipo de ativos biológicos que possuem, a forma de mensuração e a tática de 
mensuração utilizada, se valor justo ou custo histórico.

Quadro 3: Tipos de ativos biológicos e métodos de mensuração.

\begin{tabular}{|c|c|c|c|}
\hline \multirow[t]{2}{*}{ Empresa } & \multicolumn{3}{|l|}{ Tipos de Ativo Biológico } \\
\hline & Valor Justo & & Custo Histórico \\
\hline $\begin{array}{l}\text { Brasilagro - Cia Bras. de Prop. } \\
\text { Agrícolas }\end{array}$ & $\begin{array}{l}\text { Soja, Milho, Sorgo, e Gado } \\
\text { bovino }\end{array}$ & $M A^{*} / \mathrm{FC}^{* *}$ & -- \\
\hline BRF S.A. & Aves e Suínos & $\mathrm{FC}$ & --- \\
\hline Celulose Irani S.A. & Floresta de Pinus & $\mathrm{FC}$ & - \\
\hline Cia Ferro Ligas da Bahia - Ferbasa & Floresta de Eucalipto & $\mathrm{FC}$ & \begin{tabular}{|c|}
--- \\
\end{tabular} \\
\hline Duratex S.A. & Floresta de Eucalipto e Pinus & $\mathrm{FC}$ & $\begin{array}{l}\text { Floresta de Eucalipto e } \\
\text { Pinus (até } 1 \text { ano) }\end{array}$ \\
\hline Fibria Celulose S.A. & Floresta de Eucalipto & $\mathrm{FC}$ & Floresta de Eucalipto (até 2 anos) \\
\hline Grazziotin S.A. & |-- & --- & Soja e Milho \\
\hline Itausa Investimentos Itaú S.A. & Floresta de Eucalipto e Pinus & $\mathrm{FC}$ & -- \\
\hline JBS S.A. & Bovinos & MA & Aves, Ovinos e Suínos \\
\hline Klabin S.A. & Floresta de Eucalipto e Pinus & $\mathrm{FC}$ & $\begin{array}{l}\text { Eucalipto (até } 3 \text { anos) Pinus (até } 5 \\
\text { anos) }\end{array}$ \\
\hline Marfrig Global Foods S.A. & Bovinos & MA & Aves \\
\hline Minerva S.A. & Bovinos & MA & --- \\
\hline SLC Agrícola S.A. & -- & --- & $\begin{array}{l}\text { Soja, Milho, Algodão e Cana-de- } \\
\text { Açúcar }\end{array}$ \\
\hline Suzano Holding S.A. & Floresta de Eucalipto & FC & --- \\
\hline Suzano Papel e Celulose S.A. & Floresta de Eucalipto & $\mathrm{FC}$ & -- \\
\hline Trevisa Investimentos S.A. & $\begin{array}{l}\text { Florestas de Pinus, Eucaliptos } \\
\text { e Rebanho de Gado }\end{array}$ & $\mathrm{SFC}$ & -- \\
\hline WLM - Indústria e Comércio S.A. & Rebanho Bovino & MA & --. \\
\hline
\end{tabular}

A empresa Brasilagro destaca-se por conter dois tipos de ativos biológicos com bases de avaliação distintas; o rebanho bovino, mensurado com base no mercado ativo e, ativos biológicos como soja, milho e sorgo, avaliados pelo fluxo de caixa descontado. No mesmo sentido, a JBS S.A., empresa do setor de alimentos processados, avalia o rebanho bovino a valor de mercado e os demais animais que não mantêm mercado ativo, como aves e suínos, a preço de custo, sem abordagem a valor justo. Esses resultados vão ao encontro do estudo de Wanderley et al. (2012) que identificou que as empresas do setor de alimentos processados/carnes e derivados demonstravam os ativos biológicos em desconformidade ao CPC 29. Na presente pesquisa esse índice se reverteu.

Algumas empresas, principalmente as que detêm florestas de pinus e eucalipto avaliam as árvores plantadas ao método de custo até um certo tempo de vida das florestas, pelo fato dos custos estarem muito assemelhados ao valor justo, ou pela dificuldade de mensuração, porém, à medida que passam a ter valor comercial, elas passam a sofrer a abordagem de fluxo de caixa descontado. Em semelhança ao foco deste estudo, Prado et al. (2012), demonstraram a importância na evidenciação das demonstrações contábeis, de acordo com as normas contábeis vigentes. Ambas as pesquisas defendem a adequação às normas não para buscar melhores resultados, mas sim para representar a situação econômica da empresa de forma fidedigna, a fim de auxiliar o usuário da informação na análise e na tomada de decisão.

De forma geral os resultados destacam como a normativa está sendo atendida pelas empresas da análise, onde os ativos biológicos com mercado ativo representam maior índice de conformidade ao CPC 29 
em relação aos ativos avaliados a valor justo por meio da técnica fluxo de caixa.

\section{CONCLUSÕES}

O estudo teve como seu objetivo analisar as informações de ativos biológicos contidas nas demonstrações contábeis de 18 empresas listadas no índice B3 nos anos de 2017 e 2018. Foi analisado o nível de adequação ao CPC 29, por meio da utilização de um checklist com 17 itens referentes à adequada evidenciação dos ativos biológicos.

A complexidade do assunto se dá pela forma que deve ser abordado o valor justo. Alguns ativos podem ser avaliados pelas características de mercado ativo, o que facilita a mensuração dos ativos biológicos pelo valor justo. $O$ problema principal é para empresas que não têm ativos biológicos avaliados por condições de mercado ativo, como por exemplo, a Celulose Irani S.A., que apresentou melhores índices de conformidade ao checklist, porém, suas florestas de pinus não possuem mercado ativo que facilite a mensuração. Nesses casos observou-se a técnica do valor justo com base no fluxo de caixa descontado.

Para exemplificar a diferença na abordagem do valor justo quando se tem um mercado ativo tem-se a Marfrig Global Foods S.A, que possui no ativo biológico rebanho de gado bovino avaliado de acordo com o mercado ativo. A empresa detém também aves que não possuem mercado ativo e são avaliadas ao preço de custo. A justificativa é de que o preço de custo desse ativo muito se assemelha ao que seria apurado pelo fluxo de caixa descontado. Entre as 18 empresas abordadas, a Karsten S.A. não atendeu a nenhum item do checklist pesquisado em relação ao CPC 29. A empresa registrou nas demonstrações contábeis o mesmo saldo de ativos biológicos a longo prazo em 2017 e em 2018, não foi identificada informação da composição do saldo nas notas explicativas.

De forma geral, a evidenciação do CPC 29 nas empresas listadas foi mais bem atendida por empresas que possuem ativos biológicos mensurados a valor de mercado. Fato esse que se dá pela segurança na mensuração desse ativo. Notou-se que a alternativa utilizada por empresas que possuem ativos biológicos sem mercado ativo, foi de apurar a avaliação dos ativos biológicos com base no fluxo de caixa descontado.

Os ativos biológicos têm reconhecida importância para alguns setores pela expressividade do volume monetário ou pela possibilidade de geração de receita, e por isso é necessário que sejam avaliados adequadamente, a fim de auxiliar nas tomadas de decisões e facilitar aos investidores avaliarem se o investimento poderá render benefícios ou não. Nesse sentido, recomenda-se aplicação do modelo de pesquisa para os períodos subsequentes, com agregação de itens que possam trazer variáveis que ampliem os patamares da análise, como por exemplo, se a evolução da informação contábil nos períodos trouxe consigo evolução também nos níveis de conformidade às normativas. Convém, de forma adicional, analisar a evidenciação nas notas explicativas voltadas aos ativos biológicos.

\section{REFERÊNCIAS}

ARRUDA, F. C. S.; FERREIRA, V. S.; SILVA, A.. Tratamento Contábil e suas divulgações quanto aos ativos biológicos e produtos agrícolas-IAS (International Accounting Standards) 41-com correlação ao CPC 29 (Pronunciamento Contábil Brasileiro 29). Revista Interatividade, v.4, n.2, p.68-76, 2016. 
AZEVEDO, G. M.. Fatores influentes na aplicação da IAS 41 'Agricultura' nas empresas vitivinícolas portuguesas. Revista de Educação e Pesquisa em Contabilidade, v.5, n.3, p.86116, 2011.

BARRETO, A. A. R.; OLIVEIRA, D. L.; RODRIGUES, S.; PONTES, J. A.; PORTO, W. S.. Piscicultura Integrada à Agroindústria: uma Proposta de Fluxo Contábil de Acordo com os CPCS 29 e 16. RACE: Revista de Administração, Contabilidade e Economia, v.15, n.3, p.915-944, 2016.

BARROS, C. D. C.; SOUZA, F. J. V.; ARAÚJO, A. O.; SILVA, J. D. G.; SILVA, M. C.. O impacto do valor justo na mensuração dos ativos biológicos nas empresas listadas na BM\&F Bovespa. Revista de Contabilidade do Mestrado em Ciências Contábeis da UERJ, v.17, n.3, p.41-59, 2013.

CARVALHO, F.; PAULO, E.; SALES, I.; IKUNO, L.. Ativos biológicos: evidenciação das empresas participantes do Ibovespa. Custos e Agronegócio, v.9, n.3, p.106-130, 2013.

EINSWEILLER, A. C.; FISCHER, A.. Efeitos da aplicação de valor justo no ativo biológico de uma empresa do ramo de celulose e papel. Revista Catarinense da Ciência Contábil, v.12, n.37, p.24-34, 2013.

FINATELLI, J. R.; ORTEGA, G. R.. Ativos biológicos: nível de transparência e evidenciação nas demonstrações contábeis. Revista Brasileira de Contabilidade, v.20, n.196, p.66-79, 2013.

GIL, A. C.. Como elaborar projetos de pesquisa. 5 ed. São Paulo: Atlas, 2010.

HOLTZ, L.; ALMEIDA, J. E. F.. Estudo sobre a relevância e a divulgação dos ativos biológicos das empresas listadas na BM\&FBOVESPA. Sociedade, Contabilidade e Gestão, v.8, n.2, 2013

KRUGER, S. D.; BORDIGNON, A.; MAZZIONI, S.; GUBIANI, C. A.. Tratamento contábil dos ativos biológicos e produtos agrícolas em cooperativas de Santa Catarina. Reunir: Revista de Administração, Contabilidade e Sustentabilidade, v.4, n.3, p.42-61, 2014.

MACEDO, V. M.; CAMPAGNONI, M.; ROVER, S.. Ativos biológicos nas companhias abertas no Brasil: Conformidade com o CPC 29 e associação com características empresariais. Sociedade, Contabilidade e Gestão, v.10, n.3, 2015.

MACHADO, V. N.; VICTOR, F. G.; MATTS, J. S.. Ativos biológicos: uma análise da aderência ao CPC 29 pelas companhias listadas na BM\&FBOVESPA de 2007 a 2015. Revista ConTexto, v.16, n.34, p.35-72, 2016.

MARTINS, A. S.; OLIVEIRA, D. L.. Reconhecimento contábil da degeneração de ativos biológicos para a produção no cultivo de árvores frutíferas. Revista Contemporânea de Contabilidade, v.11, n.22, p.73-94, 2014.
PLAIS, P. M.. Os impactos da nova metodologia de contabilização, no Brasil, dos ativos biológicos e derivativos sobre os indicadores nas análises econômico-financeiras feitas por instituições financeiras para financiamento de empresas do setor de commodities agrícolas. Revista de Finanças Aplicadas, v.1, p.1-16, 2010.

PRADO, T. A. R.; BERNARDINO, F. F. M.. A mudança de critério contábil para os ativos biológicos e seus impactos no valuation das empresas brasileiras do segmento da agricultura. Revista CEPPG-Cesuc, p.9-22, 2012.

CPC. Pronunciamento Técnico CPC 29, de 07 de agosto de 2009. Ativo Biológico e Produto Agrícola. Brasília, 2009.

CPC. Pronunciamento Técnico CPC 46, de 07 de dezembro de 2012. Mensuração do Valo Justo. Brasília, 2012.

RAUPP, F. M.; BEUREN, I. M.. Metodologia da pesquisa aplicável às ciências. In: Como elaborar trabalhos monográficos em contabilidade: teoria e prática. São Paulo: Atlas, 2006. p.76-97.

RODRIGUES, A. A. D. O. N.; FERREIRA, R. D. C. L.; MANTOVANI, T. B.; KRAUTER, E.. Uma comparação da qualidade da informação contábil entre as empresas de capital misto e as de controle privado no Brasil. Revista de Gestão, Finanças e Contabilidade, v.1, n.6, p.76-91, 2016.

SILVA, R. J.; MACIEL, S. A.; HACHENHAAR, G. I.; SANTOS, J. R.; DUTRA, F. M.. Mensuração do ativo biológico em gado nelore fêmea de uma propriedade rural na cidade de Dourados/MS. Comunicação \& Mercado, UNIGRAN, v.5, n.12, p.49-58, 2016

SILVA, R. L. M.; NARDI, P. C. C.; RIBEIRO, M. S.. Gerenciamento de resultados e valorização dos ativos biológicos. Brazilian Business Review, v.12, n.4, p.1, 2015.

SCHERCH, C. P.; NOGUEIRA, D. R.; OLAK, P. A.; CRUZ, C. V. O. A.. Nível de conformidade do CPC 29 nas empresas brasileiras: uma análise com as empresas de capital aberto. RACE: Revista de Administração, Contabilidade e Economia, v.12, n.2, p.459- 490, 2013.

TALASKA, A.; OLIVEIRA, D. L.. Nível de disclosure de ativos biológicos nas empresas listadas na BM\&FBOVESPA: análise pós-adoção do valor justo. Revista de Contabilidade do Mestrado em Ciências Contábeis da UERJ, v.21, n.3, p.2239, 2017.

VIEIRA, E. T. V.; ITAVO, L. C. V.; ARANHA, J. A. M.. Mensuração de ativos biológicos pelo método de custo histórico e valor justo na pecuária leiteira. Interações, Campo Grande, v.17, n.1, p.145-153, 2016.

WANDERLEY, C. A. N.; SILVA, A. C.; LEAL, R. B.. Tratamento contábil de ativos biológicos e produtos agrícolas: uma análise das principais empresas do agronegócio brasileiro. Pensar Contábil, v.14, n.53, 2012.

A CBPC - Companhia Brasileira de Produção Científica (CNPJ: 11.221.422/0001-03) detém os direitos materiais desta publicação. Os direitos referem-se à publicação do trabalho em qualquer parte do mundo, incluindo os direitos às renovações, expansões e disseminoc̃os da contribuicão, bem como outros direitos subsidiários. Todos os trabalhos publicados eletronicamente poderão (a) preservam os direitos autorais, mas não têm permissão para a publicação da contribuição em outro meio, impresso ou digital, em português ou em tradução. 